\title{
Distribution and conservation of the Sino- Mongolian beaver Castor fiber birulai in China
}

\author{
Hong Jun CHU and ZHIGANG JiAng
}

\begin{abstract}
The Sino-Mongolian beaver Castor fiber birulai lives in the Ulungur watershed in China and Mongolia, an area little known to the people outside this region. We recorded the number of families, adults, subadults and juveniles at each of three beaver lodges in the Bulgan Beaver Nature Reserve in 2003, 2006 and 2007. Along the whole Ulungur watershed in China in each of the 3 years we conducted surveys for the beaver and estimated the total population based on the area of food caches. We recorded 135, 167 and 145 Sino-Mongolian beaver colonies and estimated a population $472-599,543-700$ and $508-645$ beavers in 2003, 2006 and 2007, respectively. From 1989 to 2007 the number of human households in the Bulgan Nature Reserve increased by $112 \%$ and the population by $71 \%$. Consequently human activities in the river valley, including collection of wood for fuel, increased. We also surveyed the site of a relocation of C. f. birulai from the Bulgan River to the Ertix River in 1992 but found no sign of living beavers. The population of the Sino-Mongolian beaver in China is small and restricted geographically. Threats, such as habitat modification and deterioration and competition with people for wood, continue. We recommend that the Bulgan Beaver Nature Reserve be expanded by a transfrontier agreement with the appropriate authorities in Mongolia, and that a plan for sustainable wetland management and restoration is required.
\end{abstract}

Keywords Beaver, Castor fiber birulai, Mongolia, Ulungur watershed, China.

\section{Introduction}

7 here are two beaver species: the American beaver Castor I canadensis and the Eurasian beaver Castor fiber (Müller-Schwarze \& Sun, 2003). C. fiber has recovered across much of its range as a result of conservation programmes and has been assessed for the IUCN Red List as of Least Concern (IUCN, 2008). The Asian populations, however, are small and threatened and conservation measures are urgently required (IUCN, 2008). The Sino-Mongolian beaver

\footnotetext{
HongJun CHU North-west Institute of Plateau Biology, Chinese Academy of Sciences, Xining, China, Graduate School of the Chinese Academy of Sciences, Beijing, China, and Wildlife Conservation Office, Altay Prefecture, Xinjiang, China.

ZHIGANG JIANG (Corresponding author) Institute of Zoology, Chinese Academy of Sciences, Beijing, China, 10010. E-mail jiangzg@ioz.ac.cn

Received 3 November 2008. Revision requested 13 December 2008. Accepted 13 January 2009.
}

C. f. birulai is a threatened subspecies that lives only in the Ulungur watershed between Mongolia and China, comprising the Bulgan River, which flows from Mongolia, and the Major and Minor Qinghe and Chargan Rivers, which flow into the Ulungur River and into Ulungur Lake in Altay Prefecture, Xinjiang Uygur Autonomous Region (Fig. 1). Russian authorities introduced both C. fiber and C. canadensis to the Amur river (Halley \& Rosell, 2002) but there is no evidence that populations established on the bank of the Amur river in Chinese territory.

C. f. birulai is one of the rarest and least known aquatic mammals in China, with only one substantial population known (in the Bulgan River Beaver Reserve along the Xinjiang-Mongolian border, with an estimated 500 individuals; IUCN, 2008). C. f. birulai was listed as endangered by the US Fish and Wildlife Service in 1980 (USFWS, 1999) and is listed as a First Class National Key Protected Wild Animal Species in both China and Mongolia.

C. f. birulai lives in rivers that pass through desert and thus the biology of this subspecies is typical of a beaver living in an environment that has limited productivity. Reproductive rate is low and it is difficult to breed the subspecies in captivity ( $\mathrm{Lu}, 1981)$. The forested river valleys that are the typical habitat of C. f. birulai have many human settlements and intensively farmed or grazed areas; these activities are threatening the survival of C. f. birulai (Lu, 1981; Liang, 1985). To protect the subspecies' population and habitats two reserves were established, in the Bulgan River valleys in Mongolia and China, in 1965 and 1980, respectively.

The first survey of C. f. birulai was carried out on the Major and Minor Qinghe, Chargan and Bulgan Rivers in the 1950 ( $(\mathrm{Lu}, 1981)$, and a further survey was conducted at the time of the establishment of the Bulgan Beaver Nature Reserve in 1980 (Liang, 1985). In 1989, $860 \mathrm{~km}$ of surveys were conducted along the Major and Minor Qinghe, Chargan and Bulgan Rivers of the Ulungur watershed in China; the number of beaver families was recorded, the total number of beavers estimated, and conservation recommendations made (Shao, 1990). However, because of a shortage of funds no surveys of C.f. birulai in the Ulungur River valley were conducted in the 1990 s apart from occasional patrols by wildlife managers along the Ulungur watershed in China and the $250 \mathrm{~km}$ Bulgan River in Mongolia. The lack of surveys and monitoring has hindered the implementation of effective conservation measures for the species. We therefore conducted surveys for C. f. birulai along the Major and Minor Qinghe, Chargan, Bulgan Rivers and other sections of the whole Ulungur watershed in China in 2003, 2006 and 2007. Based 


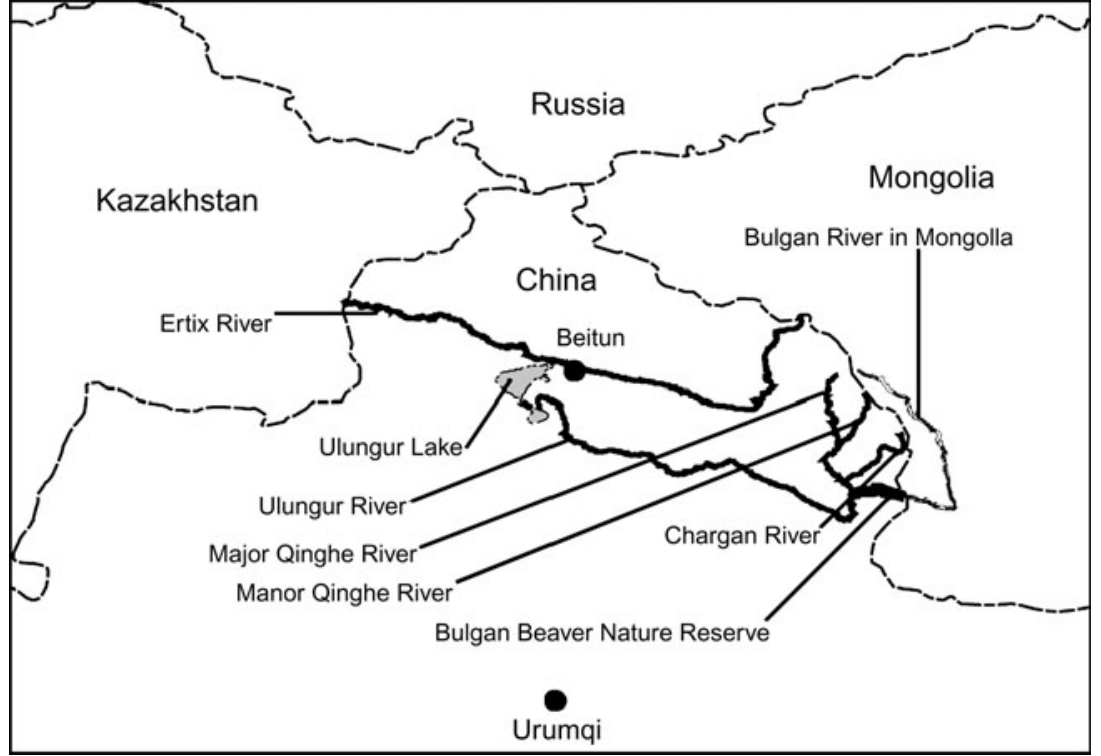

FIG. 1 The Ulungur watershed in Altay Prefecture, Xinjiang Uygur Autonomous Region, China, showing the rivers surveyed, including that of the Bulgan Beaver Nature Reserve. on our results and other available data, we make conservation recommendations for this threatened subspecies.

\section{Study area}

The rivers of the Ulungur watershed flow through 16 Xiang (townships, an administrative level under the county government in China) in Qinghe, Fuyun and Fuhai Counties in Xinjiang (Fig. 1). The oases along the rivers are surrounded by the moraine of Mount Altay and Gurbantunggut Gobi. The altitude of the watershed is $460-4,000 \mathrm{~m}$, and the climate is continental cold temperate, with a 6-month winter, a frost free period of c. 67-115 days, and maximum and minimum temperatures of 34.3 and $-49.7^{\circ} \mathrm{C}$, respectively. The area is dry, annual precipitation is only one tenth of the evaporation, and c. $33 \%$ of the annual precipitation falls as snow. Depth of snow cover is usually c. $80 \mathrm{~cm}$ and the frozen soil layer is $\mathrm{c} .70 \mathrm{~cm}$ deep in winter.

\section{Methods}

Along the $50 \mathrm{~km}$ river valley of the Bulgan Beaver Nature Reserve (Fig. 1) we interviewed the head of every household in 2003, 2006 and 2007 to record the number of people and the number of livestock held (there are Kazak, Han, Uygur and Mongol ethnic groups in the region but Kazaks comprise the majority of the population).

A beaver colony is defined as a group of beavers occupying a pond or a stretch of stream, using a common food supply, and maintaining a common dam or dams (Bradt, 1938). A colony may use several lodges or bank dens in summer but only a single food cache in the autumn and one lodge in winter (Hay, 1958). A colony site, as defined in this study, was a pond or series of ponds used by a colony of beavers throughout the year. Individual sites were usually separated by a section of stream unaltered by beavers. If there was no unaltered section of stream the use of separate food caches in the autumn was presumed to distinguish colonies (Hay, 1958).

We made dawn and dusk observations, following Easter-Pilcher (1990), Osmundson \& Buskirk (1993) and Rosell et al. (2006), of three C. $f$. birulai families in the Bulgan Beaver Nature Reserve in September and October of 2003, 2006 and 2007. One person conducted observations upstream of a beaver lodge whilst a second observed downstream, over 3 consecutive days.

In October of 2003, 2006 and 2007 we searched the whole Ulungur watershed for beaver food caches, lodges and foraging sites. In November of all 3 years we then used standard beaver survey methods (Hay, 1958; Novak, 1977; Svendsen, 1980; Shao, 1990) in all locations where we found evidence of beavers, recording vegetation composition and coverage, food caches, incisor cutting width by beavers on tree trucks, size of hind footprints, positions and sizes of overwinter lodges, any dams, and presence of a breathing hole on beaver lodges after snow covered the ground. We also took photos of each beaver family.

Following Easter-Pilcher (1990) we estimated the number of beavers in the whole Ulungur River watershed in China based on the food cache sizes recorded and the relationship between number of beavers and food cache size.

TABLE 1 Number of human residents and livestock in the Bulgan Beaver Nature Reserve (Fig. 1). Data for 1989 are from Shao (1990).

\begin{tabular}{lllllll}
\hline \multicolumn{7}{c}{ Number of } \\
Year & Households & residents & Sheep & Horses & Cattle & Camels \\
\hline 1989 & 329 & 2,159 & 50,969 & 2,184 & 4,677 & 1,390 \\
2003 & 601 & 3,325 & 44,226 & 1,559 & 3,635 & 885 \\
2006 & 703 & 3,749 & 22,351 & 1,709 & 3,534 & 736 \\
2007 & 698 & 3,689 & 36,698 & 1,938 & 3,534 & 684 \\
\hline
\end{tabular}


TABLE 2 Numbers of adults, subadults and juveniles, family size, and food cache area of Castor fiber birulai at three beaver lodges observed in October-November 2003, 2006 and 2007. The ranges of the data are the results of two observers, each searching for beavers either up or downstream (Easter-Pilcher, 1990).

\begin{tabular}{|c|c|c|c|c|c|}
\hline Lodge & No. of adults & No. of subadults & Juveniles & Family size & Food cache area $\left(\mathrm{m}^{2}\right)$ \\
\hline \multicolumn{6}{|l|}{2003} \\
\hline Grassland station & 1 & 0 & $0-1$ & $1-2$ & 12 \\
\hline Delehan's & 2 & 0 & $0-2$ & $2-4$ & 20.8 \\
\hline Poplar dam & 2 & $2-3$ & $2-3$ & $6-8$ & 42 \\
\hline \multicolumn{6}{|l|}{2006} \\
\hline Grassland station & 1 & $0-1$ & 0 & $1-2$ & 29.5 \\
\hline Delehan's & 2 & $0-1$ & $1-2$ & $3-5$ & 50 \\
\hline Poplar dam & 2 & $1-2$ & $2-3$ & $5-7$ & 75 \\
\hline \multicolumn{6}{|l|}{2007} \\
\hline Grassland station & 2 & $0-2$ & $1-2$ & $5-6$ & 70 \\
\hline Delehan's & 2 & 1 & $0-1$ & $2-4$ & 44 \\
\hline Poplar dam & 2 & 1 & $1-2$ & $4-6$ & 60 \\
\hline
\end{tabular}

C. $f$. birulai used to inhabit in the Ertix River but was extirpated there in the 1980 s (Lu, 1981; Liang, 1985). In a restoration attempt two $C$. $f$. birulai families, including a subadult, were translocated from the Bulgan Beaver Nature Reserve to the Ertix River, near Beitun (Fig. 1), on 12 October 1992. On 18 October 2003 we surveyed the translocation site to verify the fate of the released beavers.

We used the Kolmogorov-Smirnov Test to check normality of the data collected, and then a 1-way ANOVA to examine differences in habitat variables at colony sites between years. SPSS v. 13.0 was used for all statistical analyses (SPSS, Chicago, USA).

\section{Results}

Human activities generally increased in the region. From 1989 to 2007 the number of households in the Bulgan Beaver Nature Reserve increased by $112 \%$ and the human population by $71 \%$ (Table 1 ).

Areas of the food caches of poplar Populus canescens and Populus laurifolia twigs, and numbers of beaver families, adult, subadult and juvenile beavers at the three beaver lodges in 2003, 2006 and 2007 in Bulgan Beaver Nature Reserve are given in Table 2.

Beaver families were found on all of the rivers surveyed (Fig. 1) and there was little variation in locations of lodges between years. We recorded 135, 167 and 145 beaver colonies in 2003, 2006 and 2007, respectively. Based on the relationship between food cache area and beaver family size (Table 2), we estimated there were 472-599, 543-700, 508-645 beavers in 2003, 2006 and 2007 respectively (Table 3). Numbers of C. f. birulai families in the Ulungur watershed remained relatively stable during the study period, except that the number of beaver colonies in the Ulungur River decreased slightly (Fig. 2).

Characteristics of the habitat of $C$. $f$. birulai in the Ulungur watershed are summarized in Table 4. One-way ANOVA indicated that the altitudes of locations where C. f. birulai were found did not differ among years but that all other characteristics were significantly different between years.

The number and characteristics of located beaver dams, built to elevate the water table, are given in Table 5. Beavers debarked trees and cut tree branches and twigs to build dams where the water flow was slow, and filled dams with leaves, grasses and mud.

TABLE 3 Food cache area, number of colonies, number of beavers per colony and estimated total number of Castor fiber birulai in the Ulungur watershed (Fig. 1) in 2003, 2006 and 2007.

\begin{tabular}{|c|c|c|c|c|c|c|c|c|c|c|c|}
\hline \multicolumn{3}{|c|}{ Area of food cache $\left(\mathrm{m}^{2}\right)$} & \multicolumn{3}{|c|}{ No. of colonies } & \multicolumn{3}{|c|}{ No. of beavers per colony } & \multicolumn{3}{|c|}{ Total no. of beavers } \\
\hline 2003 & 2006 & 2007 & 2003 & 2006 & 2007 & 2003 & 2006 & 2007 & 2003 & 2006 & 2007 \\
\hline$\leq 10$ & $\leq 20$ & $\leq 18$ & 10 & 10 & 9 & 1 & 1 & 1 & 10 & 10 & 9 \\
\hline $10.1-15$ & $20.1-30$ & $18.1-30$ & 18 & 23 & 17 & $1-2$ & $1-2$ & $1-2$ & $18-36$ & $23-46$ & $17-34$ \\
\hline $15.1-20$ & $30.1-40$ & $30.1-38$ & 20 & 37 & 19 & $2-3$ & $2-3$ & $2-3$ & $40-60$ & $74-111$ & $38-57$ \\
\hline $20.1-25$ & $40.1-50$ & $38.1-45$ & 27 & 31 & 33 & $3-4$ & $3-4$ & $3-4$ & $81-108$ & $93-124$ & $99-132$ \\
\hline $25.1-30$ & $50.1-70$ & $45.1-60$ & 22 & 25 & 26 & $4-5$ & $4-5$ & $4-5$ & $88-110$ & $100-125$ & $104-130$ \\
\hline $30.1-35$ & $70.1-85$ & $60.1-80$ & 16 & 16 & 21 & $5-6$ & $5-6$ & $5-6$ & $80-96$ & $80-96$ & $105-126$ \\
\hline $35.1-40$ & $85.1-100$ & $80.1-100$ & 13 & 12 & 11 & $6-7$ & $6-7$ & $6-7$ & $78-91$ & $72-84$ & $66-77$ \\
\hline$>40$ & $>100$ & $>100$ & 11 & 13 & 10 & $7-8$ & $7-8$ & $7-8$ & $77-88$ & $91-104$ & $70-80$ \\
\hline Total & & & 137 & 167 & 145 & & & & $472-599$ & $543-700$ & $508-645$ \\
\hline
\end{tabular}




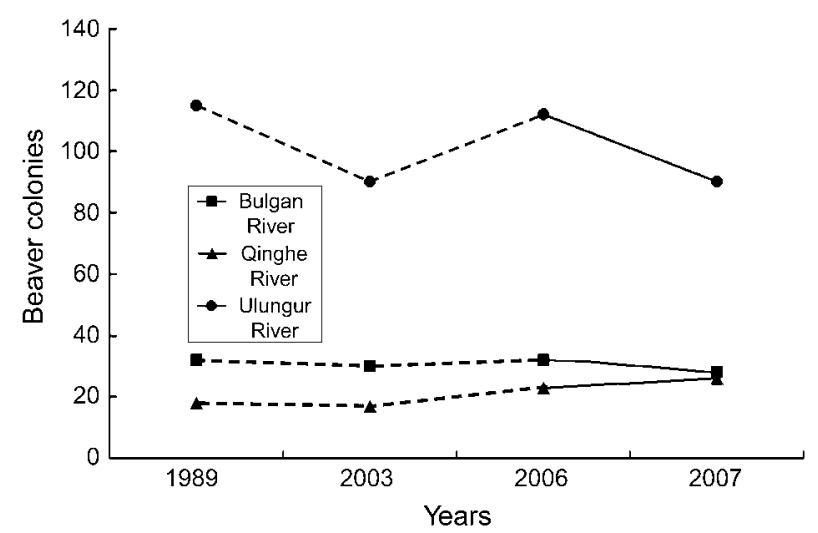

FIG. 2 Number of Sino-Mongolian beaver families in the Bulgan, Qinghe and Ulungur Rivers (Fig. 1). Data for 1989 are from Shao (1990).

We did not discover any trace of C.f. birulai in the Ertix River where they were released in 1992, despite a thorough search up and downstream of the release site.

\section{Discussion}

There are many reports of the dam-building behaviour of beavers, especially of the American beaver. Berry (1923) reported American beavers building dams up to $65.5 \mathrm{~m}$ long but $C$. f. birulai do not usually build dams because they live in deep water rivers. However, a severe drought in the Bulgan River in August 1982 caused the flow to reduce to $0.31-0.41 \mathrm{~m}^{3} \mathrm{sec}^{-1}$, only $1.0-1.3 \%$ of the average flow volume. There was almost no water in the upper river, and C.f. birulai built dams to increase the water level (Liang, 1985). We found that C. f. birulai built dams in areas of shallow water, presumably to elevate the water table to cover up the entrance of the lodge to protect cubs. The current dam-building behaviour of C. f. birulai in China may reflect the deterioration of their habitat.

From mid October to mid November is the best season for surveying the Sino-Mongolian beaver, as for the America beaver (Swank \& Glover, 1948; Payne, 1981, 1982; Swenson et al., 1983; Robel \& Fox, 1993; McTaggart \& Nelson, 2003) and other subspecies of C. fiber (Hartman, 1994; Halley \& Rosell, 2002; Rosell et al., 2006). If we had started the surveys earlier the beavers would have not yet have started building their lodges, observation of which is the main method of counting beavers. If the survey was conducted after late November, the beaver lodges would already have been covered by snow and therefore difficult to locate.

The size of C.f. birulai food caches that we recorded was smaller than reported by Lu (1993), possibly because our surveys were 1 month earlier than his. A food cache is the sign of overwinter activity. Osmundson \& Buskirk (1993) argued that American beavers stop caching foods when the water freezes and that thus the area of food cache is not correlated with family size. However, Lu (1993) and Easter-Pilcher (1990) affirmed a correlation between food cache and family size, and we also found the family size of C.f. birulai is related to the area of the food cache.

Although the Bulgan River is only c. $10 \%$ of the total length of the Ulungur watershed in China, c. $23 \%$ of the C.f. birulai population in China live along this river. The Bulgan Beaver Nature Reserve thus plays a key role in the conservation of the species in China. However, the beaver population in the $50 \mathrm{~km}^{2}$ reserve may be at carrying capacity and therefore consideration should be given to enlargement of the Reserve. One possibility would be the establishment of a transfrontier Nature Reserve. This would require negotiations between the Wildlife Management Authority in Altay Prefecture and its Mongolian counterpart.

We estimated there were 472-599 Sino-Mongolian beavers in 2003, 543-700 in 2006 and 508-645 in 2007 in the Ulungur River watershed of China. Surveys in 1991 estimated there were c. 300 C. f. birulai along the Bulgan and Chovd Rivers in Mongolia (Stubbe et al., 1991), and this number remained stable up to 2005 (Ducroz et al., 2005). In 1983 the total population of C. f. birulai was estimated to be 800 (Lavrov, 1983) and was presumed stable up to 2002 (Halley \& Rosell, 2002). Compared with the census in 1989

TABLE 4 Characteristics of the habitat of C. f. birulai in Ulungur watershed (Fig. 1) in 2003, 2006 and 2007 (all values are mean \pm SD), and results of ANOVA $(F)$ comparisons between years.

\begin{tabular}{|c|c|c|c|c|}
\hline Habitat characteristic & $2003(\mathrm{n}=137)$ & $2006(\mathrm{n}=167)$ & $2007(\mathrm{n}=145)$ & $F(\mathrm{P})$ \\
\hline Altitude (m) & $876.45 \pm 201.60$ & $880.49 \pm 215.72$ & $889.59 \pm 215.11$ & $0.236(0.790)$ \\
\hline River bank height above river water level (m) & $1.42 \pm 0.33$ & $1.14 \pm 0.49$ & $1.55 \pm 0.45$ & $34.405(<0.001)$ \\
\hline River bank water depth (m) & $1.39 \pm 0.42$ & $1.83 \pm 0.49$ & $1.61 \pm 0.47$ & $32.363(<0.001)$ \\
\hline $\begin{array}{l}\text { Maximum tree trunk diameter } 10 \mathrm{~cm} \text { above } \\
\text { ground of trees cut by beaver }(\mathrm{m})\end{array}$ & $0.24 \pm 0.17$ & $0.32 \pm 0.19$ & $0.19 \pm 0.20$ & $26.597(<0.001)$ \\
\hline $\begin{array}{l}\text { Tree branch diameter } 10 \mathrm{~cm} \text { above ground of } \\
\text { trees cut by beaver }(\mathrm{m})\end{array}$ & $0.02 \pm 0.01$ & $0.04 \pm 0.01$ & $0.02 \pm 0.01$ & $27.666(<0.001)$ \\
\hline Longest harvesting distance to river bank (m) & $19.50 \pm 4.06$ & $54.64 \pm 52.99$ & $50.92 \pm 46.72$ & $41.657(<0.001)$ \\
\hline Shortest harvesting distance to river bank (m) & $2.37 \pm 1.16$ & $2.51 \pm 1.97$ & $0.04 \pm 0.09$ & $7.013(<0.001)$ \\
\hline Arboreal cover at colony (\%) & $0.16 \pm 0.13$ & $0.29 \pm 0.17$ & $0.44 \pm 0.19$ & $97.998(<0.001)$ \\
\hline Furthest cutting signs found upstream (m) & $82.19 \pm 40.37$ & $163.89 \pm 104.09$ & $188.82 \pm 128.21$ & $26.325(<0.001)$ \\
\hline Furthest cutting signs found downstream (m) & $23.70 \pm 35.70$ & $127.04 \pm 86.45$ & $132.16 \pm 108.24$ & $23.677(<0.001)$ \\
\hline
\end{tabular}


TAвLE 5 Characteristics of C. f. birulai dams located in the Ulungur watershed (Fig. 1) in 2003, 2006 and 2007. All values are mean \pm SD.

\begin{tabular}{lclllll}
\hline Years & $\mathrm{n}$ & $\begin{array}{l}\text { Length of } \\
\text { dam }(\mathrm{m})\end{array}$ & $\begin{array}{l}\text { Width at bottom } \\
\text { of dam }(\mathrm{m})\end{array}$ & $\begin{array}{l}\text { Width at top } \\
\text { of dam }(\mathrm{m})\end{array}$ & $\begin{array}{l}\text { Height of bottom } \\
\text { of dam }(\mathrm{m})\end{array}$ & $\begin{array}{l}\text { Water table } \\
\text { level elevated }(\mathrm{m})\end{array}$ \\
\hline 2003 & 6 & $15.71 \pm 6.41$ & $1.08 \pm 0.28$ & $0.42 \pm 0.14$ & $0.76 \pm 0.26$ & $0.58 \pm 0.29$ \\
2006 & 16 & $18.31 \pm 29.74$ & $0.84 \pm 0.68$ & $0.52 \pm 0.25$ & $0.92 \pm 0.22$ & $0.55 \pm 0.20$ \\
2007 & 12 & $22.86 \pm 33.98$ & $0.45 \pm 0.17$ & $0.74 \pm 0.36$ & $1.01 \pm 0.4$ & $0.60 \pm 0.19$ \\
\hline
\end{tabular}

(Shao, 1990) our surveys indicate a potential decline in the number of beaver colonies in the Ulungur River (Fig. 2). Causes for this decline could be the logging and land reclamation that has occurred in the river valley and construction of a dam in the upper Bulgan River, which lowered the water table in the river. The increasing human population, and a concomitant increase in wood-burning stoves, means that the human population is competing with beavers for the wood of poplars.

The Mongolian Wildlife Management Authority has successfully relocated C. f. birulai from the Bulgan River to the Chovd River, where the beaver had been earlier extirpated (Halley \& Rosell, 2002). The most recent population assessment, in 2004, recorded 40 beaver lodges along the Chovd River and a population of c. 130-150 beavers (Shar, 2005). The attempted relocation of C. f. birulai to the Ertix River in China appears to have been unsuccessful, although field surveys found traces of beavers during the year immediately after the relocation (Huang, 1993). The number of beavers relocated, only five, was probably insufficient. In contrast, four C. f. birulai were translocated to the Chovd River in 1959-1960, and 35 in 1974-1985 (Stubbe \& Dawaa, 1986).

There is a cluster of populated oases in the Ulungur River watershed in northern Xinjiang (Shen et al., 2001), and C. f. birulai is a potential flagship species for conservation in these areas because the status of the beaver reflects the condition of the river and wetlands of the watershed (Chu, 1993). For the protection of the biodiversity of the Ulungur River watershed and its oases, and of the only Sino-Mongolian beaver population in China, a plan for sustainable wetland management and restoration is required. An alternative energy source for the human population is also required, to reduce their dependence on fuelwood collected in the river valleys. Any such plan will need to include reforestation of the river valleys.

\section{Acknowledgements}

The research was supported by the China Exploration and Research Society, Division of Wild Flora and Fauna Conservation of the SFA, Wild Flora and Fauna Research and Development Center of the SFA, Chinese Academy of Sciences, Innovative Research International Partnership Project (CXTDS2005-4), Division of Wild Flora and Fauna Conservation of Forestry Bureau of the Xinjiang Uygur
Autonomous Region, Bulgan Beaver Nature Reserve, and Altay Management Station of the Kalamaili Nature Reserve. Qi Yinjie, Chen Gang, Mahashati, Jianabur, Li Wenqing, Yang Zhaoqing, Guo Wei and Li Xiaoyun helped us with the surveys. Professor Sun Lixing gave us advice on preparation of the manuscript.

\section{References}

BERRY, S.S. (1923) Observations on a Montana beaver canal. Journal of Mammalogy, 4, 92-103.

BRADT, G. (1938) A study of beaver colonies in Michigan. Journal of Mammalogy, 19, 139-162.

Chu, H. (1993) Survey on beaver Castor fiber birulai. Chinese Nature, 54, 12-13. [in Chinese]

Ducroz, J., Stubbe, M., Saveljev, A.P., Heidcke, D., Samjaa, R., Ulevičius, A. et al. (2005) Genetic variation and population structure of the Eurasian beaver Castor fiber in Eastern Europe and Asia. Journal of Mammalogy, 86, 1059-1067.

Easter-Pilcher, M. (1990) Cache size as an index to beaver colony size in north-western Montana. Wildlife Society Bulletin, 18, 110-113.

Halley, D.J. \& Rosell, F. (2002) The beaver's reconquest of Eurasia: status, population development and management of a conservation success. Mammal Review, 32, 153-178.

Hartman, G. (1994) Long-term population development of a reintroduced beaver (Castor fiber) population in Sweden. Conservation Biology, 8, 713-717.

HAY, K.G. (1958) Beaver census methods in the Rocky Mountain region. Journal of Wildlife Management, 22, 395-402.

Huang, B. (1993) Relocation of beaver C. fiber birulai. MSc thesis, Shandong University, Jinan, China. [in Chinese with English summary]

IUCN (2008) 2008 IUCN Red List of Threatened Species. IUCN, Gland, Switzerland. Http://www.iucnredlist.org [accessed 20 January 2009].

Lavrov, L.S. (1983) Evolutionary development of the genus Castor and taxonomy of the contemporary beavers of Eurasia. Acta Zoologica Fennica, 174, 87-90.

LiAnG, C. (1985) The dam-building habit in beaver Castor fiber birulai. Scientia Silvae Sinicae, 21, 253-258. [in Chinese with English abstract]

Lu, H. (1981) Distribution and ecological characteristics of beaver Castor fiber birulai in China. Journal of Shandong University (Natural Science Edition), 4, 1-7. [in Chinese with English abstract]

Lu, H., Yu, C., Shao, W., Zhen, G. \& Chu, H. (1993) Problems on protection and multiplication of beaver Castor fiber birulai in China. In Evolution of Mammalian Fauna under the Influence of Human Activity (ed. W. Xia), pp. 17-20. Chinese Science and Technology Press, Beijing, China. [in Chinese with English abstract] 
McTaggart, C.T. \& Nelson, T.A. (2003) Composition and demographics of beaver (Castor canadensis) colonies in central Illinois. American Midland Naturalist, 150, 139-150.

Müller-Schwarze, D. \& Sun, L. (2003) The Beaver: Natural History of a Wetlands Engineer. Cornell University Press, Ithaca, USA.

Nolet, B. \& Rosell, F. (1998) Comeback of the beaver Castor fiber: an overview of old and new conservation problems. Biological Conservation, 83, 165-173.

Nova K, M. (1977) Determining the average size of beaver families. Journal of Wildlife Management, 41, 751-754.

Osmundson, L. \& Buskirk, S.W. (1993) Size of food caches as a predictor of beaver colony size. Wildlife Society Bulletin, 21, 64-69.

Payne, N.F. (1981) Accuracy of aerial censusing for beaver colonies in Newfoundland. Journal of Wildlife Management, 45, 1014-1016.

Payne, N.F. (1982) Colony size, age, and sex structure of Newfoundland beaver. Journal of Wildlife Management, 46, 655-661.

RoвeL, R.J. \& Fox, L.B. (1993) Comparison of aerial and ground survey techniques to determine beaver colony densities in Kansas. The Southwestern Naturalist, 38, 357-361.

Rosell, F., Parker, H. \& Steifetten, F. (2006) Use of dawn and dusk sight observations to determine colony size and family composition in Eurasian beaver Castor fiber. Acta Theriologica, 51, 107-112.

Shao, W. (1990) Population ecology study on C. fiber birulai in Xinjiang. MSc thesis, Shandong University, Jinan, China. [in Chinese with English abstract]

SHAR, S. (2005) Distribution of beavers in Chovd River. Kyzyl, 7, 316-317.

Shen, Y., Wang, J., Wu, G. \& Han, D. (2001) Oasis of China. Henan University Press, Zhenzhou, China. [in Chinese]

Stubie, M. \& Dawaa, N. (1986) Die autochtone zentralasiatische Biberpopulation. Zoologische Abhandlungen, 41, 93-103.
Stubie, M., Dawaa, N. \& Heidecke, D. (1991) The autochthonous Central Asiatic beaver population in the Dzungarian Gobi. In Mammals in the Palaearctic Desert: Status and Trends in the Sahara-Gobian Region (eds J.A. McNeely \& V.M. Neronov), pp. 258-268. The Russian Academy of Sciences and the Russian Committee for the UNESCO programme on Man and the Biosphere, Moscow, Russia.

Svendsen, G.E. (1980) Population parameters and colony composition of beaver (Castor canadensis) in south-east Ohio. America Midland Naturalist, 104, 47-56.

SWANK, W.G. \& GLOVER, F.A. (1948) Beaver censusing by airplane. Journal of Wildlife Management, 12, 214.

Swenson, J.E., Knapp, S.J., Martin, R. \& Him, T.C. (1983) Reliability of aerial cache surveys to monitor beaver population trends on prairie rivers in Montana. Journal of Wildlife Management, 47, 697-703.

USFWS (US Fish \& WiLdlife SERvice) (1999) Endangered and Threatened Wildife and Plants (50 CFR17.11 and 17.22). US Fish \& Wildlife Service, Division of Endangered Species, Washington, DC, USA.

\section{Biographical sketches}

HongJun Chu has been studying the Sino-Mongolian beaver Castor fiber birulai for nearly 20 years, and has been working in the Forestry Bureau of the Altay Prefecture, Xinjiang, since 1991. ZHIGANG JIANG's interests are focused on the conservation of wild fauna and particularly the threatened mammals of China $\mathrm{He}$ is also Executive Director of the Endangered Species Scientific Commission of China (the National CITES Scientific Authority of China). 